\title{
SEMISYNTHESIS OF HUMAN INSULIN UTILIZING CHEMICALLY MODIFIED CARBOXYPEPTIDASE Y
}

\author{
by \\ KLAUS BREDDAM $^{1)}$ and JACK T. JOHANSEN ${ }^{2)}$ \\ "Chemical Department, Carlsberg Laboratory \\ Gamle Carlsberg Vej 10, DK-2500 Copenhagen Valby \\ "Carlsberg Biotechnology Ltd., \\ A/S Tagensvej 16, DK-2200 Copenhagen N
}

\begin{abstract}
Keywords: Enzymatic synthesis, protein semisynthesis, carboxypeptidase $\mathrm{Y}$, insulin, mercuric chloride, methyl mercuric iodide
\end{abstract}

\begin{abstract}
It has previously been demonstrated that the C-terminal alanyl residue in the B-chain of porcine insulin can be exchanged with a threonyl residue in a carboxypeptidase $Y$ catalyzed transpeptidation reaction using threonine amide as nucleophile. However, with this procedure the transpeptidation product, human insulin amide, was obtained in relatively low yields. In the present paper it is demonstrated that mercury halide derivatives of CPD-Y catalyze the transpeptidation reaction with porcine insulin effectively and human insulin amide could be isolated in high yield. It is also demonstrated that deamidation of human insulin amide to yield essentially homogeneous human insulin can be achieved using CPD-Y modified with methyl mercuric iodide (Me-Hg-CPD-Y).
\end{abstract}

\section{INTRODUCTION}

The ability of CPD-Y to specifically catalyze the exchange of the C-terminal amino acid residue in peptides with various other amino acid residues by a transpeptidation reaction makes it a useful tool in protein semisynthesis (1, 2). Such a transpeptidation reaction has been used to convert porcine insulin to human insulin amide which in a subsequent CPD-Y catalyzed deamidation reaction was converted to human insulin (3). Normally, CPD-Y catalyzed transpeptidation reactions result in the formation of only two products, the transpeptidation product and the hydrolysis product. However, with porcine insulin and with Bz-Lys-Ala-OH, a model peptide of the C-terminal segment of the B-chain of porcine insulin, other products accumulate in the reaction mixtures (5). These side reactions occur because the C-terminal peptide bond in these substrates is cleaved very slowly rendering

\footnotetext{
Abbreviations: $\mathrm{Bz}=$ benzoyl; $\mathrm{CPD}-\mathrm{Y}=$ carboxypeptidase $\mathrm{Y} ; \mathrm{DMF}=\mathrm{N}, \mathrm{N}$-dimethylformamide; TEAP $=$ triethylammonium phosphate buffer; Hepes $=\mathrm{N}$-2-hydroxyethylpiperazine- $\mathrm{N}$-2-ethane sulfonic acid; HPLC $=$ high performance liquid chromatography. Since only the C-terminal of the B-chain of insulin is involved in these reactions, INS-Pro-Lys-Ala-OH is used as an abbreviation of porcine insulin. Other insulin derivatives are thus abbreviated accordingly: INS-Pro-Lys-OH $=\operatorname{des}(\mathrm{Ala})^{\mathrm{B} 30}$ insulin; INS-Pro-Lys-Thr- $\mathrm{NH}_{2}=\operatorname{des}(\mathrm{Ala})^{\mathrm{B} 30}\left(\mathrm{Thr}_{\mathrm{N}} \mathrm{NH}_{2}\right)^{\mathrm{B} 30}$ insulin, etc. 'Hg-CPD-Y = mercuric chloride inactivated CPD-Y, I-Hg-CPD-Y $={ }^{+} \mathrm{Hg}-\mathrm{CPD}-\mathrm{Y}$ in the presence of iodide; $\mathrm{Br}-\mathrm{Hg}-\mathrm{CPD}-\mathrm{Y}={ }^{+} \mathrm{Hg}$-CPD-Y in the presence of bromide, etc.; $\mathrm{Mes}=2(\mathrm{~N}$-morpholino)ethane sulfonic acid; Me-Hg-CPD-Y = CPD-Y modified with methylmercuric iodide. Abbreviations of amino acids, amino acid derivatives are according to the guideline of the UIPAC-IUB Commission on Biochemical Nomenclature.
} 
both the transpeptidation and hydrolysis reactions sufficiently slow for other reactions to compete. The additional products formed are of two categories: condensation products formed by peptide elongation without exchange of the C-terminal amino acid residue and secondary reaction products formed by further reactions of the transpeptidation and hydrolysis products. Thus, the specificity of CPD-Y, i.e. the low rate of cleavage of substrates with a lysyl residue in the $P_{1}$ position (SCHECHTER-BERGER nomenclature (12)), complicated transpeptidation reactions with porcine insulin. In this connection it was of interest that CPD-Y modified with mercuric halides hydrolyzed substrates with a

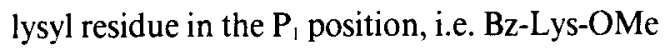
and Bz-Lys-Ala-OH, several times faster than did unmodified CPD-Y (4). In the present paper it is demonstrated that mercury halide derivatives of CPD-Y catalyze the transpeptidation reaction with porcine insulin effectively and human insulin amide could be isolated in high yield. It is also demonstrated that deamidation of human insulin amide to yield essentially homogeneous human insulin can be achieved using CPD-Y modified with methyl mercuric iodide (Me-Hg-CPD-Y).

\section{MATERIALS AND METHODS}

\subsection{Materials}

CPD-Y was isolated as previously described (7). It was checked that the preparation was free of Protease A by the assay of LEE and RIORDAN (9). Bz-Lys-Ala-OH was prepared by enzymatic synthesis (5). Porcine insulin was a gift from Nordisk Insulinlaboratorium, Denmark, through the courtesy of Dr. B. HANSEN. L-threonine amide and L-threonine amide hydrochloride were prepared by Dr. O.H. MANSCHER, Carlsberg Biotechnology Ltd. Chromatographic materials were products of Pharmacia, Sweden and methylmercuric iodide was obtained from Koch-Light Laboratories, England. Mercuric chloride and all other reagents and solvents were of analytical purity and obtained from Merck, W. Germany.

$\mathrm{Me}-\mathrm{Hg}-\mathrm{CPD}-\mathrm{Y}$ and ${ }^{+} \mathrm{Hg}-\mathrm{CPD}-\mathrm{Y}$ were prepared in the following manner: to $1 \mathrm{ml} \mathrm{CPD}-Y$ (11.9 $\mathrm{mg} \times \mathrm{ml}^{-1}$ in water) was added $0.1 \mathrm{ml} 0.5$
M-Hepes pH 7.5 and $25 \mu \mathrm{l} 10 \mathrm{mM}-\mathrm{HgCl}_{2}$ (in water) or $25 \mu 10 \mathrm{~mm}$-methylmercuric iodide (in DMF). The mixture was left at room temperature for $15 \mathrm{~min}$ and then kept on ice for up to 8 hours. Cl-Hg-CPD-Y, Br-Hg-CPD-Y, I-Hg$\mathrm{CPD}-\mathrm{Y}$ and $\mathrm{CN}-\mathrm{Hg}-\mathrm{CPD}-\mathrm{Y}$ were formed by adding the inactive ${ }^{+} \mathrm{Hg}-\mathrm{CPD}-\mathrm{Y}$ to $0.5 \mathrm{M}-\mathrm{KCl}$, $20 \mathrm{mM}-\mathrm{KBr}, 10^{-4} \mathrm{M}-\mathrm{KI}$ or $10^{-4} \mathrm{M}-\mathrm{KCN}$, respectively. These concentrations of halide ions are essential in order to saturate ${ }^{+} \mathrm{Hg}$-CPD-Y (4).

\subsection{Methods}

All enzymatic reactions were performed in a $\mathrm{pH}$ stat and the $\mathrm{pH}$ was kept constant by titration with $\mathrm{NaOH}$ solutions. The transpeptidation reactions using Bz-Lys-Ala-OH as acyl component were performed using the following conditions: $5 \mathrm{~mm}$-Bz-Lys-Ala-OH, $0.5 \mathrm{M}-\mathrm{H}-\mathrm{Thr}-$ $\mathrm{NH}_{2} \mathrm{HCl}, 12 \mu \mathrm{M}-{ }^{+} \mathrm{Hg}-\mathrm{CPD}-\mathrm{Y}, 1 \mathrm{M}-\mathrm{KCl}, \mathrm{pH}$ 7.5. $100 \mu \mathrm{l}$ aliquots were diluted into $1 \mathrm{ml}$ acetonitrile to stop the reaction and then analyzed by HPLC, using the program and equipment described in ref. 5 .

\subsubsection{Preparation of human insulin amide}

Transpeptidation reactions with porcine insulin were performed under the following conditions: $15 \mathrm{mg} \times \mathrm{ml}^{-1}$ crystalline porcine insulin, 1 $\mathrm{M}-\mathrm{H}-\mathrm{Thr}-\mathrm{NH}_{2}, 1 \mathrm{M}$-urea, 5-13 $\mu \mathrm{M}-{ }^{+} \mathrm{Hg}-\mathrm{CPD}-\mathrm{Y}$, $10^{-4} \mathrm{M}-0.5 \mathrm{M}$-halide, $\mathrm{pH} 7.5-8.25$. The reaction was followed by HPLC (Figure 1) and when the desired amount of porcine insulin was converted the reaction was stopped by adjusting $\mathrm{pH}$ to 1.7 with $6 \mathrm{M}-\mathrm{HCl}$. If precipitates appeared, $1 \mathrm{M}$-acetic acid was added until all material was dissolved. The insulin mixture was separated from enzyme and low molecular weight compounds by chromatography on a Sephadex G-50 fine column, equilibrated with $1 \mathrm{M}$-acetic acid (13), and lyophilized. The resulting product was dissolved in $0.01 \mathrm{M}$-Tris, $2.5 \mathrm{M}$-urea, $0.05 \mathrm{M}-\mathrm{NaCl}$, pH 7.5 and applied to a DEAE Sepharose CL 6B column equilibrated with the same buffer. Elution of the column with a linear $\mathrm{NaCl}$ gradient from 0.05 to $0.30 \mathrm{M}$ separated the reacted insulin in three peaks I, II and III as previously described $(3,5)$. These peaks contain the following insulin species: (Peak I) INS-Pro-Lys-Thr- $\mathrm{NH}_{2}$, INS- 


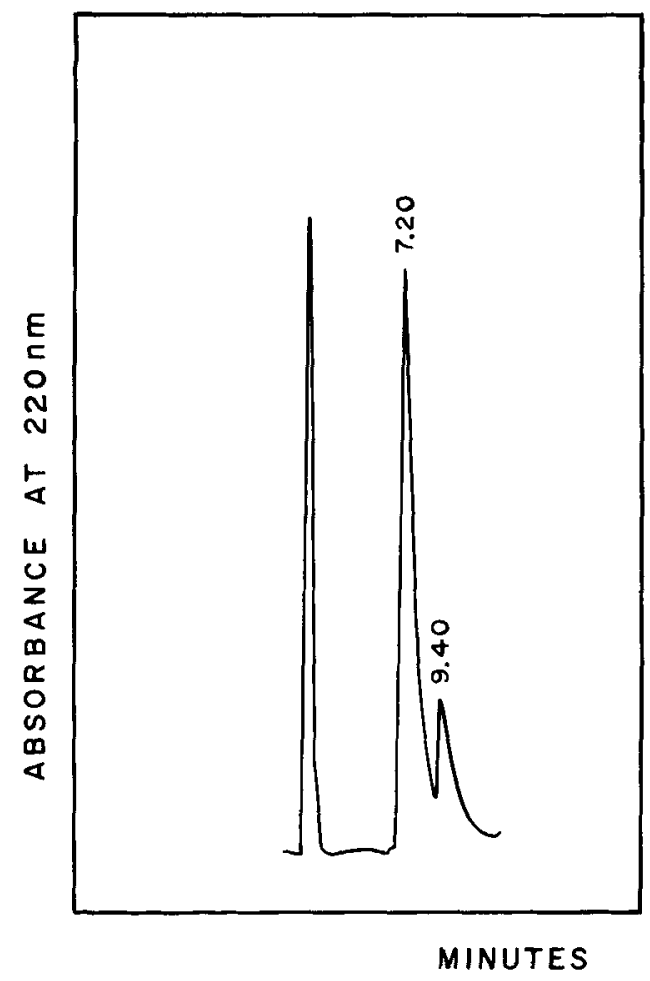

Figure 1. HPLC analysis of transpeptidation product from porcine insulin.

Waters equipment as described in ref. 5 , equipped with a Supelco $\mathrm{LC} 18,5 \mu(0.4 \times 25 \mathrm{~cm})$ reverse phase column, equilibrated with $0.1 \mathrm{M}-\left(\mathrm{NH}_{4}\right)_{2} \mathrm{SO}_{4}, 28 \%$ $\mathrm{CH}_{3} \mathrm{CN}$, was used. Aliquots of the reaction mixture $(30 \mu \mathrm{l})$ were diluted into $200 \mu \mathrm{l} 1 \mathrm{M}$-acetic acid. The extent of the reaction could be followed by the decrease in the peak at 7.20 and the increase in the peak at 9.40 .

Pro-Lys-Thr-Thr-NH $\mathrm{NH}_{2}$ and INS-Pro-Lys-AlaThr-NH $\mathrm{NH}_{2}$; (Peak II) INS-Pro-Lys-Ala-OH, INSPro-Lys-Thr-OH, INS-Pro-Lys-OH and INSPro-Thr-NH $\mathrm{NH}_{2}$; (Peak III) various degradation products, respectively. The pooled fractions from each of the peaks were desalted by gelfiltration on a Sephadex G-25 column which was equilibrated and eluted with $1 \mathrm{M}$-acetic acid, and lyophilized. From the results of amino acid analysis combined with the relative areas of the peaks the relative amounts of the various insulin components in the reaction mixture could be calculated according to the methods previously used (3). Analysis of the insulin derivatives eluting in peak I was also performed by digestion with CPD-Y using the following conditions: 0.5 $\mathrm{mg}$ insulin was dissolved in $100 \mu \mathrm{l} 0.05 \mathrm{M}$ Hepes, 2 mM-EDTA, pH 7.5 and $50 \mu \mathrm{g}$ CPD-Y was added. After incubation for $30 \mathrm{~min}$ at $37^{\circ} \mathrm{C}$ the reaction was terminated by addition of $10 \mu \mathrm{l}$ $1 \mathrm{M}-\mathrm{HCl}$ and the mixture was applied directly to the amino acid analyzer. The amount of alanine released by this reaction was used to calculate the content of the condensation product, INS-ProLys-Ala-Thr- $\mathrm{NH}_{2}$, eluting in peak $\mathrm{I}$.

\subsubsection{Deamidation of human insulin amide}

The insulin derivatives in peak I was subjected to a CPD-Y catalyzed deamidation reaction thereby converting human insulin amide to human insulin. The reactions were performed at pH 7.5 to 10.0 using a concentration of insulin

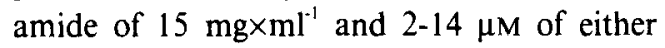
CPD-Y or Me-Hg-CPD-Y. The reaction could not be performed at $\mathrm{pH}$ values lower than 7.5 due to lack of solubility of the insulin amide. The reaction could be followed by HPLC employing the procedure used to follow the transpeptidation reaction (Figure 1). The insulin amides eluted at 9.40 minutes and the deamidated product eluted at approximately the same position as porcine insulin ( 7.20 minutes). When the desired degree of deamidation was obtained, the reaction was terminated by addition of $\mathrm{HCl}$ to adjust the $\mathrm{pH}$ to approximately 1.7 . The resulting human insulin was separated from unreacted insulin amide by chromatography on DEAE Sepharose CL 6B as described above. Peak II, containing the human insulin, was desalted by gelfiltration on Sephadex G-25, equilibrated with $1 \mathrm{M}$-acetic acid, and then lyophilized. The purity of the isolated human insulin was determined by HPLC using a procedure similar to the one described by INOUYE et al. (6). A Supelco LC $18 \mathrm{DB}, 5 \mu(0.4 \times 15 \mathrm{~cm})$ reverse phase column and the same equipment as described in ref. 1 was used.

\section{RESULTS AND DISCUSSION}

\subsection{Transpeptidation reactions}

We have previously shown that the conversion of porcine insulin, INS-Pro-Lys-Ala-OH, to human insulin amide, INS-Pro-Lys-Thr- $\mathrm{NH}_{2}$, 


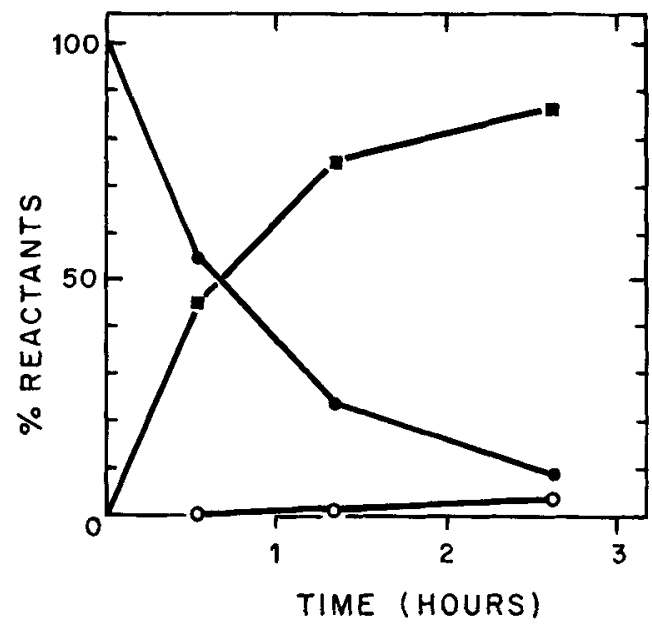

Figure 2. Cl-Hg-CPD-Y catalyzed transpeptidation using Bz-Lys-Ala-OH as acyl component and H-Thr$\mathrm{NH}_{2}$ as amine component.

For conditions see section 2.2. - $\bullet-$ Bz-Lys-Ala$\mathrm{OH},-\mathrm{O}-\mathrm{O}-\mathrm{Bz}-\mathrm{Lys}-\mathrm{OH},-\boldsymbol{-}-\mathbf{-}-\mathrm{Bz}-\mathrm{Lys}-\mathrm{Thr}-\mathrm{NH}_{2}$.

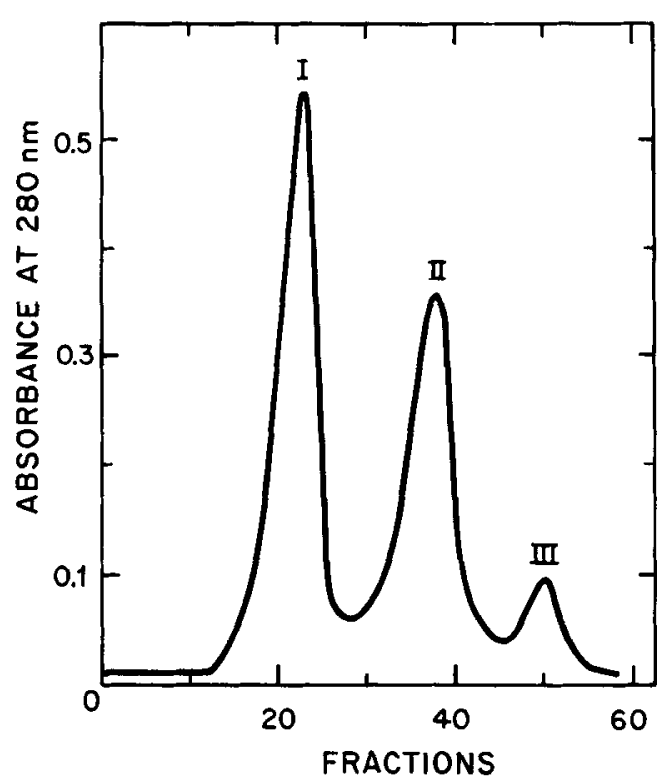

Figure 3. Chromatography on DEAE Sepharose CL $6 \mathrm{~B}$ of the insulin derivatives obtained after the following reaction:

$15 \mathrm{mg} \times \mathrm{ml}^{-1}$ insulin, $1 \mathrm{~m}$-urea, $1.0 \mathrm{M}-\mathrm{H}-\mathrm{Thr}-\mathrm{NH}_{2}$, $5 \mu \mathrm{M}-{ }^{+} \mathrm{Hg}-\mathrm{CPD}-\mathrm{Y}, \mathrm{pH} 7.5$ (adjusted with $\mathrm{HBr}$ ). Reaction time $130 \mathrm{~min} .90 \mathrm{mg}$ "insulin" was applied to the column which was eluted as described in section 2.2. Fraction size: $10 \mathrm{ml}$.
Table I.

Influence of $\mathrm{pH}$ on the $\mathrm{Br}-\mathrm{Hg}-\mathrm{CPD}-\mathrm{Y}$ catalyzed transpeptidation reaction. Amino acid compositions of peaks I, and II from DEAE chromatography.

\begin{tabular}{|c|c|c|c|c|}
\hline & & Peak I & Peak II & Peak III \\
\hline \multirow{4}{*}{$\mathrm{pH} 7.5^{\text {a) }}$} & Thr & 3.01 & 2.44 & - \\
\hline & Lys & 0.99 & 0.57 & - \\
\hline & Ala & 1.08 & 1.39 & - \\
\hline & Area $(\%)$ & 52 & 42 & 7 \\
\hline \multirow{4}{*}{$\mathrm{pH} 7.75^{\mathrm{b})}$} & Thr & 2.98 & 2.59 & - \\
\hline & Lys & 1.01 & 0.53 & - \\
\hline & Ala & 1.06 & 1.25 & - \\
\hline & Area $(\%)$ & 50 & 41 & 9 \\
\hline \multirow{4}{*}{$\mathrm{pH} 8.0^{\circ}$} & Thr & 3.18 & 2.69 & - \\
\hline & Lys & 0.96 & 0.52 & - \\
\hline & Ala & 1.07 & 1.16 & - \\
\hline & Area $(\%)$ & 48 & 42 & 11 \\
\hline \multirow{4}{*}{$\mathrm{pH} 8.25^{\mathrm{d}}$} & Thr & 3.44 & 2.66 & - \\
\hline & Lys & 0.96 & 0.56 & - \\
\hline & Ala & 1.03 & 1.11 & - \\
\hline & Area (\%) & 39 & 45 & 15 \\
\hline
\end{tabular}

Reaction conditions: $1 \mathrm{M}-\mathrm{H}-\mathrm{Thr}-\mathrm{NH}_{2}, 1 \mathrm{M}$-urea, 15 $\mathrm{mg} \times \mathrm{ml}^{-1} \mathrm{Zn}$-insulin, pH adjusted with 4.4 M-HBr. The following reaction times and concentrations of ${ }^{+} \mathrm{Hg}$ CPD-Y was used: a) $5 \mu \mathrm{M}, 130 \mathrm{~min}$, b) $6 \mu \mathrm{M}, 130$ min, c) $8 \mu \mathrm{M}, 100 \mathrm{~min}$, d) $13 \mu \mathrm{M}, 80 \mathrm{~min}$. The reaction mixture was chromatographed as described in section 2. Amino acid compositions were determined after hydrolysis for 24 hours in $6 \mathrm{M}-\mathrm{HCl}$. The amino acid compositions were based on the known content in insulin of 4 glycine and 3 aspartic acid. Only the uncorrected values for $\mathrm{Thr}$, Lys and Ala are listed in the transpeptidation reactions, since these are the only amino acids affected by the reactions. The amino acid analysis of these amino acids for porcine insulin are: $\mathrm{Thr}=1.93$, Lys $=0.97$ and $\mathrm{Ala}=2.00$ and for authentic human insulin: $\mathrm{Thr}=2.87$, Lys $=0.98$ and $\mathrm{Ala}=$ 1.05 .

by means of a CPD-Y catalyzed transpeptidation reaction proceeds with a rather low yield due to lack of specificity in the transpeptidation reaction (3). Since these problems also applied to the analogous transpeptidation reactions of the model peptide Bz-Lys-Ala-OH to Bz-Lys-Thr$\mathrm{NH}_{2}(5)$, this system was used initially to study the effect of replacing CPD-Y with Cl-Hg-CPD$\mathrm{Y}$ in the reaction. It is apparent from the results shown in Figure 2 that the action of $\mathrm{Cl}-\mathrm{Hg}-\mathrm{CPD}$ - 
$\mathrm{Y}$ on Bz-Lys-Ala-OH in the presence of $\mathrm{H}-\mathrm{Thr}$ $\mathrm{NH}_{2}$ resulted in the formation of only two products, Bz-Lys-OH (5\%) and Bz-Lys-Thr$\mathrm{NH}_{2}(95 \%)$, formed by hydrolysis and transpeptidation reactions, respectively. This observation confirms that the rate of transpeptidation with $\mathrm{Cl}-\mathrm{Hg}$-CPD-Y was sufficiently high to suppress the side reactions responsible for the formation of Bz-Lys-Thr-OH, Bz-Lys-Thr-Thr$\mathrm{NH}_{2}$ and Bz-Lys-Ala-Thr- $\mathrm{NH}_{2}$ (5). Thus, $\mathrm{Cl}-\mathrm{Hg}$ CPD-Y catalyzed the transpeptidation reaction with Bz-Lys-Ala-OH much more efficiently than unmodified CPD-Y, and therefore $\mathrm{Cl}-\mathrm{Hg}$ CPD-Y was expected to be a much better catalyst for the conversion of porcine insulin to human insulin amide.

The transpeptidation reaction with porcine insulin, INS-Pro-Lys-Ala-OH $+\mathrm{H}-\mathrm{Thr}-\mathrm{NH}_{2}$ $\rightarrow$ INS-Pro-Lys-Thr-NH $\mathrm{NH}_{2}+\mathrm{H}-\mathrm{Ala}-\mathrm{OH}$ was in the first series of experiments performed at $\mathrm{pH}$ 7.5 using $\mathrm{Br}-\mathrm{Hg}-\mathrm{CPD}-\mathrm{Y}$ since at concentrations of $\mathrm{Cl}^{-}(>0.5 \mathrm{M})$, where ${ }^{+} \mathrm{Hg}$-CPD-Y is saturated with $\mathrm{Cr}$, the solubility of porcine insulin in the reaction mixture is only $2 \mathrm{mg} \times \mathrm{ml}^{-1}$. In a typical experiment the reaction was terminated when $84 \%$ of the porcine insulin had been consumed. The produced insulin derivatives were then separated by ion exchange chromatography in three peaks, comprising 52\% (peak I), $42 \%$ (peak II) and 6\% (peak III) of the total area (Figure 3). Using unmodified CPD-Y under the conditions listed in reference 3 resulted in significantly different relative areas of the three peaks: $21 \%$ (peak I), 61\% (peak II) and 18\% (peak III) (3). The increase in the yield of peak $I$ by replacing CPD-Y with Br-Hg-CPD-Y is important since this peak contains the human insulin amides which are converted to human insulin in the subsequent deamidation reaction (section 3.2).

Amino acid analysis (Table I) and CPD-Y digestions of the three fractions separated in Figure 3 suggested that the insulin derivatives listed in Table II had been formed in the reaction. Apparently, porcine insulin acted at $\mathrm{pH} 7.5$ as acyl component in three reactions, transpeptidation, condensation and hydrolysis to give INS-Pro-Lys-Thr- $\mathrm{NH}_{2}$, INS-Pro-Lys-Ala-Thr$\mathrm{NH}_{2}$ and INS-Pro-Lys-OH, respectively. These initial products reacted further by transpeptidation or hydrolysis reactions to give the other products listed in Table II. Production of pure human insulin by subsequent deamidation with CPD-Y required that peak I contained only INS-Pro-Lys-Thr-NH2 and INS-Pro-Lys-ThrThr- $\mathrm{NH}_{2}$ (vide infra) and transpeptidation per-

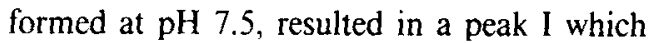
contained small amounts of INS-Pro-Lys-Ala$\mathrm{Thr}-\mathrm{NH}_{2}$ (Table II). In the analogous transpeptidation reaction with $\mathrm{Bz}-\mathrm{Lys}-\mathrm{Ala}-\mathrm{OH}$ it had been found that the formation of Bz-Lys-Ala-Thr$\mathrm{NH}_{2}$ decreased with increasing $\mathrm{pH}(5)$, and consequently the $\mathrm{pH}$ of the transpeptidation

Table II.

Insulin components in reaction mixtures listed in Table I.

\begin{tabular}{llrrrr}
\hline & & \multicolumn{3}{c}{ pH } \\
\cline { 3 - 6 } Peak & Reagents & 7.5 & 7.75 & 8.0 & 8.25 \\
\hline \multirow{2}{*}{ I } & INS-Pro-Lys-Thr-NH & 43 & 43 & 33 & 17 \\
& INS-Pro-Lys-Thr-Thr-NH & 7 & 6 & 15 & 22 \\
& INS-Pro-Lys-Ala-Thr- $\mathrm{NH}_{2}$ & 2 & $<1$ & 0 & 0 \\
& INS-Pro-Lys-Ala-OH & 15 & 9 & 5 & 3 \\
\multirow{2}{*}{ II } & INS-Pro-Lys-OH & 4 & 4 & 3 & 7 \\
& INS-Pro-Thr-NH & 18 & 19 & 20 & 15 \\
& INS-Pro-Lys-Thr-OH & 5 & 9 & 14 & 20 \\
\multirow{2}{*}{ III } & Further degradation products & 7 & 9 & 11 & 15 \\
\hline
\end{tabular}

The content of each insulin component is derived from the amino acid analysis in Table I. INS-Pro-Lys-Ala-Thr$\mathrm{NH}_{2}$ is estimated by CPD-Y digestions of the insulin derivatives eluting in peak I through the release of Ala from their C-terminals. 
K. BREDDAM \& J.T. JohanSEN: Semisynthesis of human insulin

Table III.

Influence of anion on the ${ }^{+} \mathrm{Hg}-\mathrm{CPD}-\mathrm{Y}$ catalyzed transpeptidation reaction.

\begin{tabular}{|c|c|c|c|c|c|}
\hline \multirow[b]{2}{*}{ Peak } & \multirow[b]{2}{*}{ Reactant } & \multicolumn{4}{|c|}{ Anion } \\
\hline & & $\mathrm{Cl}^{-2 !}$ & $\mathrm{Br}^{-\mathrm{hi}}$ & $\Gamma^{(1)}$ & $\mathrm{CN}^{-1 / 2}$ \\
\hline & INS-Pro-Lys-Thr-NHz & 22 & 32 & 38 & 29 \\
\hline I & INS-Pro-Lys-Thr-Thr-NH & 31 & 20 & 18 & 20 \\
\hline \multirow{4}{*}{ II } & INS-Pro-Lys-Ala-OH & 8 & 9 & 8 & 8 \\
\hline & INS-Pro-Lys-OH & 8 & 11 & 0 & 0 \\
\hline & INS-Pro-Thr-NH & 21 & 23 & 19 & 29 \\
\hline & INS-Pro-Lys-Thr-OH & 10 & 0 & 10 & 12 \\
\hline III & Further degradation products & 0 & 5 & 8 & 8 \\
\hline
\end{tabular}

Reaction conditions: All reactions contained $1 \mathrm{M}-\mathrm{H}-\mathrm{Thr}_{\mathrm{N}} \mathrm{NH}_{2}, 1 \mathrm{M}$-urea and were performed at $\mathrm{pH} 8.0$ at 32 ${ }^{\circ} \mathrm{C}$. Other reaction parameters varied: a) $2 \mathrm{mg} \times \mathrm{ml}^{-1}$ insulin, $2.5 \mu \mathrm{M}-{ }^{+} \mathrm{Hg}-\mathrm{CPD}-\mathrm{Y}, 0.5 \mathrm{M}-\mathrm{KCl}$. reaction time:

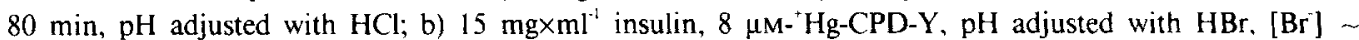
$0.2 \mathrm{M}$, reaction time. $140 \mathrm{~min}$; c) $15 \mathrm{mg} \times \mathrm{ml}^{-1}$ insulin, $10^{-4} \mathrm{M}-\mathrm{KI}, 8 \mu \mathrm{M}-{ }^{+} \mathrm{Hg}-\mathrm{CPD}-\mathrm{Y}, \mathrm{pH}$ adjusted with $\mathrm{HNO}_{3 .}$.

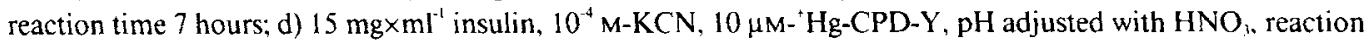
time 3 hours.

reaction with porcine insulin was varied (Table II). An increase from $\mathrm{pH} 7.5$ to 8.0 resulted in a peak I without detectable amounts of INS-ProLys-Ala-Thr- $\mathrm{NH}_{2}$, and hence, all further transpeptidation reactions were performed at this $\mathrm{pH}$.

The ratio between INS-Pro-Lys-Thr-Thr$\mathrm{NH}_{2}$ and INS-Pro-Lys-Thr- $\mathrm{NH}_{2}$ was influenced by the nature of the anion added to ${ }^{+} \mathrm{Hg}$-CPD-Y, viz. $\mathrm{Cl}, \mathrm{Br}, \mathrm{I}, \mathrm{CN}^{-}$, as exemplified in Table III. This ratio apparently increased in the sequence I-Hg-CPD-Y, Br-Hg-CPD-Y, CN-Hg-CPD-Y, $\mathrm{Cl}-\mathrm{Hg}-\mathrm{CPD}-\mathrm{Y}$, but even under the specified conditions listed in Table III variations occurred: with I the ratio varied from 0.18 to 0.47 and with $\mathrm{CN}^{-}$from 0.75 to 1.18 .

The ratio between INS-Pro-Lys-Thr-Thr$\mathrm{NH}_{2}$ and INS-Pro-Lys-Thr- $\mathrm{NH}_{2}$ was also influenced by the reaction time. Using I-Hg-CPD$\mathrm{Y}$ to catalyze the transpeptidation reaction, the content of INS-Pro-Lys-Thr-Thr- $\mathrm{NH}_{2}$ steadily increased whereas the content of INS-Pro-LysThr- $\mathrm{NH}_{2}$ reached a maximum at $44 \%$ of all insulin derivatives in the reaction mixture, and then decreased (Figure 4). The ratio between the INS-Pro-Lys-Thr- $\mathrm{NH}_{2}$ being formed and the porcine insulin being consumed in the reaction, decreased through the reaction: When $24 \%$ of the porcine insulin had been consumed INS-
Pro-Lys-Thr- $\mathrm{NH}_{2}$ constituted $83 \%$ of all derivatives formed compared to $40 \%$ when $92 \%$ of the porcine insulin had been consumed in the reaction (Figure 4).

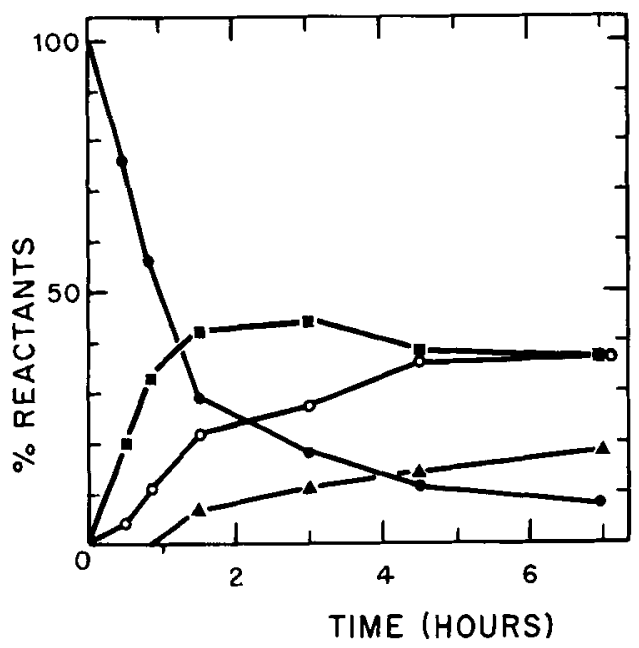

Figure 4. Influence of reaction time on the reactant composition and yield in a ${ }^{+} \mathrm{Hg}-\mathrm{CPD}-\mathrm{Y}$ catalyzed transpeptidation reaction with porcine insulin.

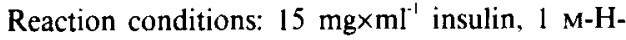
Thr-NH, 1 м-urea, $10^{-4}$ м-KI, $8 \mu$ м- ${ }^{+} \mathrm{Hg}$-CPD-Y, 32 ${ }^{\circ} \mathrm{C}$, pH 8.0 (adjusted with $\mathrm{HNO}_{3}$ ). - $\bullet-$ - INS-ProLys-Ala-OH, - - - INS-Pro-Lys-Thr-NH ${ }_{2},-\mathbf{\Delta - \Delta -}$ INS-Pro-Lys-Thr-Thr- $\mathrm{NH}_{2},-\mathrm{O}-\mathrm{O}$ - other products. 


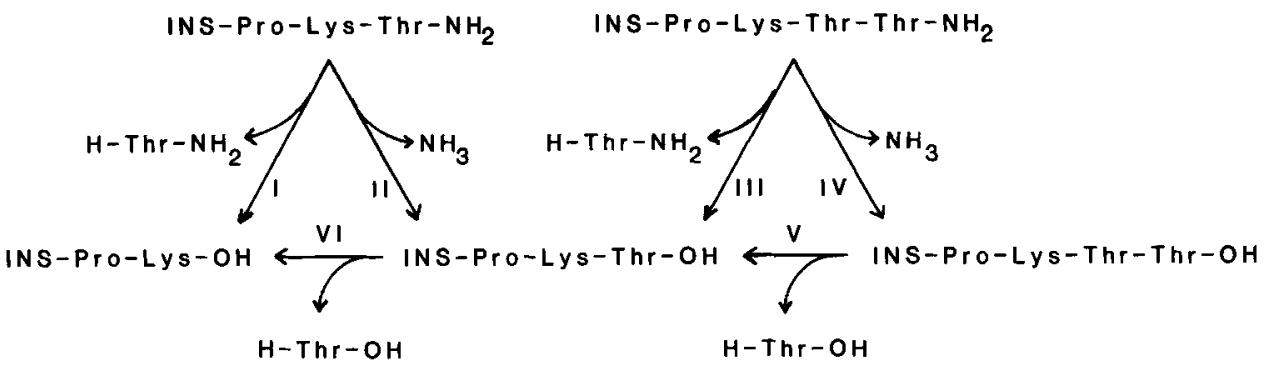

Scheme 1. Possible reactions in the action of CPD-Y on insulin amides.

\subsection{Preparation of human insulin}

CPD-Y catalyzes the release of both ammonia (amidase activity) and the C-terminal amino acid amide residue (peptidyl amino acid amide hydrolase activity) from peptide amides (1). The relative rates of these two reactions is dependent on the C-terminal sequence of the peptide amide (1). In CPD-Y catalyzed deamidations of the insulin amides obtained as peak I from ion exchange chromatography we have shown that INS-Pro-Lys-Thr- $\mathrm{NH}_{2}$ deamidates predominantly via the amidase activity (Scheme 1 , reaction II) while INS-Pro-Lys-Thr-Thr- $\mathrm{NH}_{2}$ deamidates predominantly via the peptidyl amino acid amide hydrolase activity (Scheme 1, reaction III), i.e. human insulin, INS-Pro-Lys-Thr$\mathrm{OH}$, was the predominant product from both insulin amides (3). Thus, deamidation of a mixture of INS-Pro-Lys-Thr-NH $\mathrm{NH}_{2}(20 \%)$ and INS-Pro-Lys-Thr-Thr- $\mathrm{NH}_{2}(80 \%)$, obtained after a transpeptidation reaction catalyzed by unmodified CPD-Y, yielded 96\% pure human insulin.

A mixture of INS-Pro-Lys-Thr- $\mathrm{NH}_{2}$ (84\%) and INS-Pro-Lys-Thr-Thr- $\mathrm{NH}_{2}(16 \%)$, obtained after an I-Hg-CPD-Y catalyzed transpeptidation reaction, was initially deamidated according to the procedure previously described, i.e. at $\mathrm{pH} 10$ (3). The reaction was terminated when $75 \%$ of the insulin amides had been converted as judged by HPLC analysis (see section 2.2). Ion exchange chromatography was then used to separate unreacted insulin amide eluting in peak I from deamidated material eluting in peak II. The latter was found by the HPLC method (see section 2.2) to consist of 65\% INS-Pro-Lys-Thr$\mathrm{OH}$ and $35 \%$ other insulin derivatives eluting in the position of INS-Pro-Lys-OH (Figure 5). INS-Pro-Lys-OH was presumably formed via reaction I (Scheme 1) since CPD-Y does not catalyze reaction $\mathrm{VI}$ (peptidase activity) at $\mathrm{pH} 10$ (1). The low yield of the human insulin was presumably due to the high content of INS-ProLys-Thr- $\mathrm{NH}_{2}$ in the preparation obtained as peak I after an I-Hg-CPD-Y catalyzed transpeptidation reaction.

The yield of human insulin obtained by deamidation of peak I could be improved in two ways: either by performing the transpeptidation reaction under conditions where peak I consisted exclusively of INS-Pro-Lys-Thr-Thr- $\mathrm{NH}_{2}$ or by using a more specific deamidation procedure. Unfortunately, the first option had only little applicability since the improved procedure of transpeptidation, utilizing modified CPD-Y, in no case resulted in a peak I containing more than $60 \%$ INS-Pro-Lys-Thr-Thr- $\mathrm{NH}_{2}$ (Table II). However, it was found that deamidation at lower pH's improved the yield of human insulin (Figure 6).

A further improvement in the deamidation procedure was obtained by changing the properties of the enzyme. Modification of the sulfhydryl group of CPD-Y with mercurials had previously been demonstrated to alter the specificity of the enzyme with respect to the $P_{1}$ position of the substrate (4). A modification would improve the deamidation procedure, if the rate of reaction I (Scheme 1), where a lysyl residue occupies the $P_{1}$ position, was reduced relative to reaction $I I$, where a threonyl residue occupies the $P_{1}$ position. Me-Hg-CPD-Y had these properties, since performing the deamidation reaction at $\mathrm{pH} 7.5$ using conditions as 


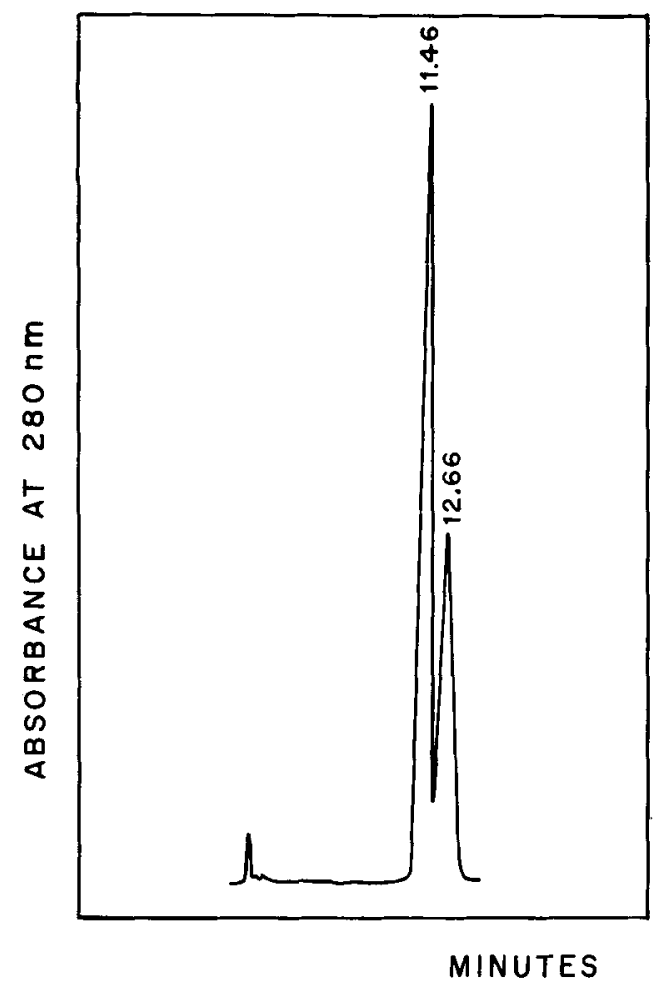

Figure 5. Purity of human insulin after deamidation at $\mathrm{pH} 10$.

The insulin amides used in the reaction were isolated by ion exchange chromatography (see section 3.1 ) as peak I after the following transpeptidation reaction

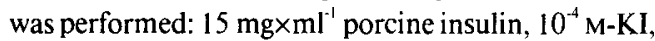
$1 \mathrm{M}-\mathrm{H}-\mathrm{Thr}_{-} \mathrm{NH}_{2}, 8 \mu \mathrm{M}-{ }^{+} \mathrm{Hg}-\mathrm{CPD}-\mathrm{Y}$, reaction time: 90 $\mathrm{min}$. The amino acid composition of peak I indicated that it was composed of $84 \%$ INS-Pro-Lys-Thr- $\mathrm{NH}_{2}$ and $16 \%$ INS-Pro-Lys-Thr-Thr- $\mathrm{NH}_{2}$. The deamidation reaction was performed with this fraction as described in section 2.2., using a CPD-Y concentration of $5.3 \mu \mathrm{M}, \mathrm{pH} 10.0$, reaction time: $55 \mathrm{~min}$. The reaction was quenched when $80 \%$ of the starting material had been converted. After isolation of the deamidated material by ion exchange chromatography (see section 2.2) its purity was checked by HPLC using a Supelco LC $18 \mathrm{DB}$ column as presented in this figure. Human insulin elutes at 11.46 while des $(\mathrm{Thr})^{\mathrm{B} 30}$ insulin and porcine insulin elutes at 12.66 as demonstrated by injection of the appropriate standard compounds.

described in Figure 6 with the exception that CPD-Y was replaced by $\mathrm{Me}-\mathrm{Hg}-\mathrm{CPD}-\mathrm{Y}$ resulted in a preparation of human insulin which contained only $3.8 \%$ contaminant eluting at the position of INS-Pro-Lys-OH.

The deamidation reactions thus far described

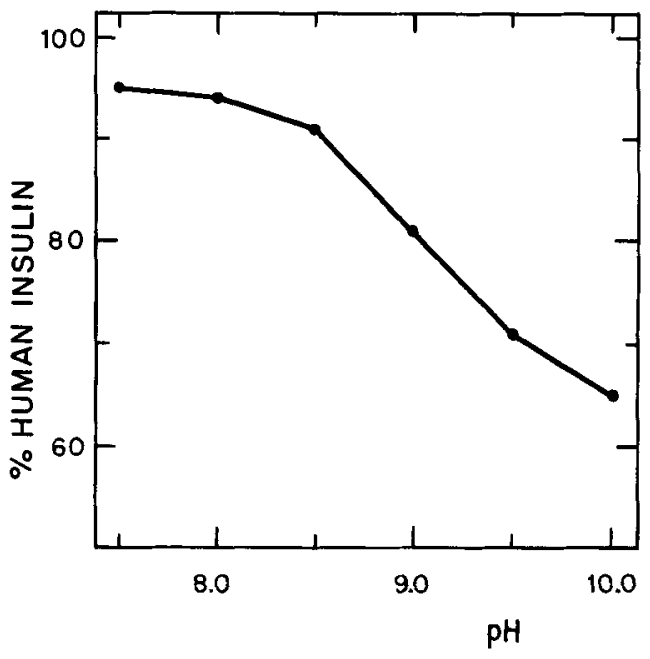

Figure 6. The dependence of the purity of human insulin on the $\mathrm{pH}$ of the deamidation.

The deamidation was performed on the same preparation of insulin amides as described in Figure 5. The reaction was performed as described in section 2.2 and quenched at a time where $75 \% \pm 10 \%$ of the insulin amides had been converted. The concentration of CPD-Y and reaction time varied: $\mathrm{pH} 7.5: 9.4 \mu \mathrm{M}$, $86 \mathrm{~min}$; $\mathrm{pH} 8.0: 7.2 \mu \mathrm{M}, 22 \mathrm{~min}$; $\mathrm{pH} 8.5: 7.2 \mu \mathrm{M}$, $26 \mathrm{~min}$; pH 9.0: $2.2 \mu \mathrm{M}, 52 \mathrm{~min}$; $\mathrm{pH} 9.5: 4.8 \mu \mathrm{M}$, $26 \mathrm{~min} ; \mathrm{pH}$ 10.0: $5.3 \mu \mathrm{M}, 55 \mathrm{~min}$. The purity indicated in the figure was determined after isolation of the deamidated fraction by ion exchange chromatography by HPLC analysis using a Supelco LC 18 DB column.

were terminated when approximately $75 \%$ of the insulin amides had been converted. However, it was observed that the purity of the human insulin also increased with the extent of the deamidation reaction (Figure 7). When $56 \%$ of the insulin amides had been deamidated a purity of $95.2 \%$ was obtained and when $92 \%$ had been deamidated a purity of $97.2 \%$ was obtained. This suggested that some of the contaminant eluting at the position of INS-Pro-Lys$\mathrm{OH}$, could be converted to INS-Pro-Lys-Thr$\mathrm{OH}$. This contaminant could not be INS-ProLys-OH itself, since this would imply a reversal of reaction VI (Scheme 1). It is more likely that the impurity is INS-Pro-Lys-Thr-Thr-OH since this insulin derivative at $\mathrm{pH} 7.5$ would be converted to INS-Pro-Lys-Thr-OH via reaction $\mathrm{V}$.

The highest purity of the human insulin $(98.2 \%)$ was obtained by deamidation of a preparation (peak I) which contained 54\% INS-Pro- 


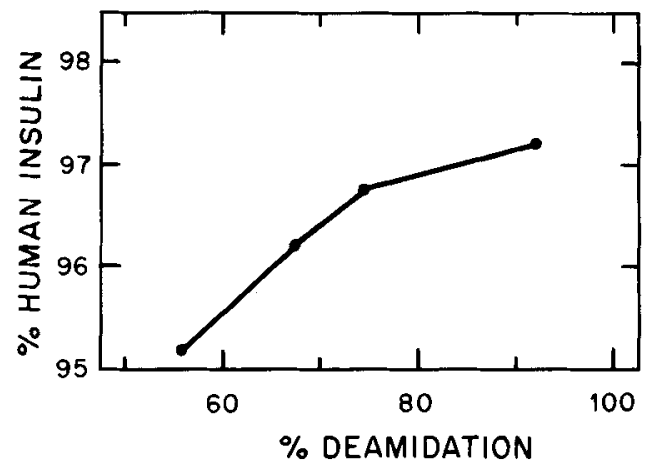

Figure 7. The influence of the degree of deamidation on the purity of the isolated human insulin.

The deamidation was performed on the same preparation of insulin amides as described in Figure 5. The reaction was performed as described in section 2.2 , using 6.0 $\mu \mathrm{M}-\mathrm{Me}-\mathrm{Hg}-\mathrm{CPD}-\mathrm{Y}$ and $\mathrm{pH}$ 7.5. Aliquots were taken at various times (the last one at $150 \mathrm{~min}$ ) and the deamidated fraction was isolated by ion exchange chromatography and its purity was checked by HPLC using a Supelco LC 18 DB column as presented in this figure.

Lys-Thr-Thr- $\mathrm{NH}_{2}$ and $46 \%$ INS-Pro-Lys-Thr$\mathrm{NH}_{2}$ (Figure 8 ) using $90-95 \%$ deamidation. The amount of impurity (1.8\%) eluting at the position of INS-Pro-Lys-OH should be compared with the $2.8 \%$ obtained by using the same procedure of deamidation with a peak I containing 16\% INS-Pro-Lys-Thr-Thr- $\mathrm{NH}_{2}$ and $84 \%$ INS-Pro-Lys-Thr- $\mathrm{NH}_{2}$ (vide supra). The difference is probably a consequence of the different contents of INS-Pro-Lys-Thr- $\mathrm{NH}_{2}$ which still under the optimized conditions of deamidation via reaction I produces small amounts of INS-Pro-Lys-OH. The amino acid composition of the human insulin obtained in this fashion was indistinguishable from the amino acid composition of authentic human insulin.

\subsection{Concluding remarks}

The use of CPD-Y modified with mercuric ions in the transpeptidation reaction with porcine insulin represents a significant improvement compared with the use of unmodified CPD-Y $(3,5)$. The yield of human insulin amide in the transpeptidation reaction increased from 20-25\% with unmodified CPD-Y to $50-55 \%$ with ${ }^{+} \mathrm{Hg}-\mathrm{CPD}-\mathrm{Y}$ in the presence of a halide ion

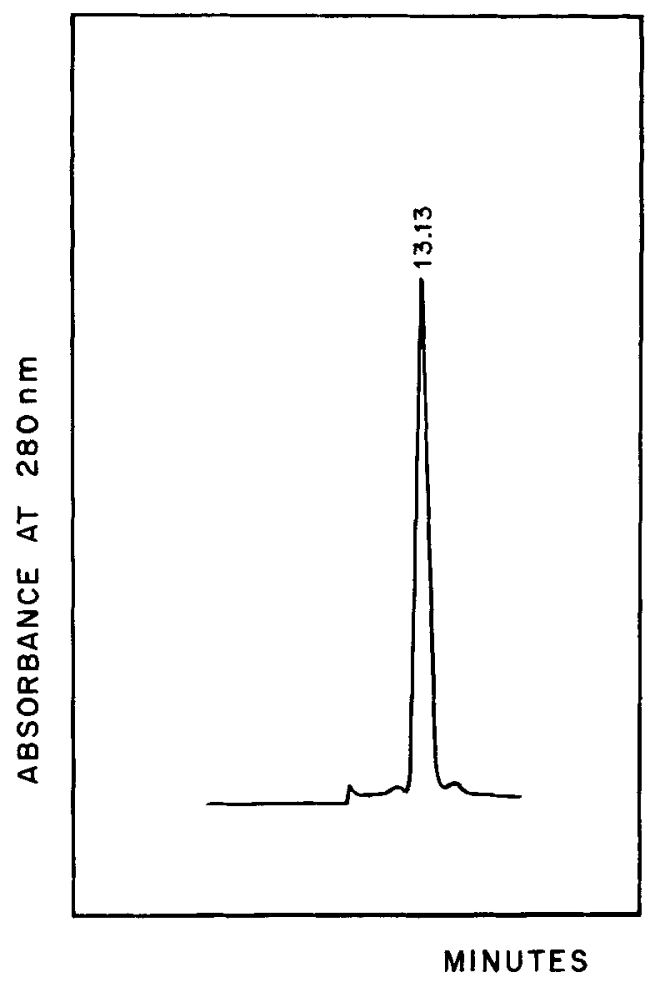

Figure 8. Purity of human insulin, prepared by deamidation of an insulin amide fraction, obtained after a transpeptidation reaction in the presence of cyanide.

The insulin amides used in the reaction were isolated by ion exchange chromatography (see section 3.1 ) as peak I after the following transpeptidation reaction

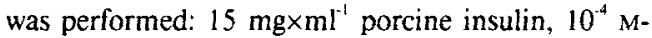
$\mathrm{KCN}, 1 \mathrm{M}-\mathrm{H}-\mathrm{Thr}-\mathrm{NH}_{2}, 10 \mu \mathrm{M}-{ }^{+} \mathrm{Hg}-\mathrm{CPD}-Y$. Reaction time: 3 hours. The amino acid composition of peak $I$ indicated that it was composed of $46 \%$ INS-Pro-LysThr-NHz and 54\% INS-Pro-Lys-Thr-Thr-NH. The deamidation reaction was performed on this fraction as described in section 2.2, using a Me-Hg-CPD-Y concentration of $19 \mu \mathrm{M}, \mathrm{pH} 7.5$, reaction time: 130 $\min$. The reaction was quenched when $90 \%$ of the starting material had been converted. After isolation of the deamidated product by ion exchange chromatography (see section 2.2) its purity was checked by HPLC using a Supelco LC 18 DB column as presented in this figure. A purity of $98.2 \%$ human insulin was obtained.

(4). This result was a consequence of an increased specificity of the modified enzyme for the transpeptidation reaction relative to the unmodified enzyme. Since the deamidation reaction can be performed with very little loss of material, the overall yield of the conversion 
of porcine insulin to human insulin is determined by the yield of the transpeptidation reaction. It should be pointed out that the yield of human insulin amide and in particular the ratio between INS-Pro-Lys-Thr-NH $\mathrm{NH}_{2}$ and INS-ProLys-Thr-Thr- $\mathrm{NH}_{2}$ critically depends on the reaction conditions (Table III, Figure 4), i.e. reaction time, enzyme concentration, and nature of halide ion.

Other procedures published for the semisynthesis of human insulin report yields of similar magnitude $(8,10,11)$. These methods proceed via INS-Pro-Lys-Thr-O'Bu which is converted to human insulin in a yield of approximately $70 \%$ by treatment with trifluoroacetic acid. The method of conversion of porcine insulin to INS-Pro-Lys-Thr-O'Bu and its yield differs between the methods. Some of the procedures are based on the specific removal of the C-terminal alanyl residue in porcine insulin by carboxypeptidase A, followed by a trypsin catalyzed condensation of $\mathrm{H}-\mathrm{Thr}-\mathrm{O}$ 'Bu to the resulting INS-ProLys-OH $(10,11)$. By this procedure, INS-ProLys-Thr-O'Bu has been prepared in $41-85 \%$ yield. Another procedure employs a trypsin catalyzed transpeptidation reaction, converting porcine insulin directly into INS-Pro-Lys-Thr$\mathrm{O}^{\prime} \mathrm{Bu}$ in a yield of $50-70 \%(8)$. However, the present procedure has the advantage of mild enzymatic reactions in all steps whereas the other procedures involve a chemical step in the removal of the $\mathrm{C}$-terminal blocking group with possible side reactions as consequence.

\section{ACKNOWLEDGEMENTS}

The authors are indebted to Professor MARTIN OTTESEN for his suggestions and for carefully revising the manuscript. Dr. O.H. MANSCHER is acknowledged for preparing threonine amide and Dr. A. ANDERSEN for his help preparing Bz-Lys-Ala-OH. The technical assistance of Mss. Pia Breddam and Merete SONNE is warmly acknowledged.

Note added in proof: Recent studies (Dr. C. OVERBALLE-PETERSEN, personal communications) have shown that use of a threonine amide preparation of higher purity increased the yields of human insulin amide to $65 \%$ using $\mathrm{I}-\mathrm{Hg}$ CPD-Y and the reaction conditions listed in the present paper.

\section{REFERENCES}

1. BReddam, K., F. Widmer \& J.T. Johansen: Carboxypeptidase $Y$ catalyzed transpeptidations and enzymatic peptide synthesis. Carlsberg Res. Commun. 45, 237-247 (1980)

2. BREddaM, K.. F. Widmer \& J.T. JOHANSEN: Carboxypeptidase $\mathrm{Y}$ catalyzed $\mathrm{C}$-terminal modifications of peptides. Carlsberg Res. Commun. 46, 121-128 (1981)

3. Breddam, K., F. Widmer \& J.T. Johansen: Carboxypeptidase $\mathrm{Y}$ catalyzed $\mathrm{C}$-terminal modification in the B-chain of porcine insulin. Carlsberg Res. Commun. 46, 361-372 (1981)

4. Breddam. K.: Modification of the single sulfhydryl group of carboxypeptidase $\mathrm{Y}$ with mercurials. Influence on enzyme specificity. Carlsberg Res. Commun. 48, 9-19 (1983)

5. Breddam, K. J.T. Johansen \& M. OtTesen: Carboxypeptidase $\mathrm{Y}$ catalyzed transpeptidation and condensation reactions. Carlsberg Res. Commun. 49, 457-462 (1984)

6. Innouye, K., K. Watanabe, K. Morihara. Y. TOCHINO \& T. KanaYa: Enzyme-assisted semisynthesis of human insulin. J. Am. Chem. Soc. 101, 751-752 (1979)

7. JOHANSEN. J.T., K. BREDDAM \& M. OTTESEN: Isolation of carboxypeptidase $Y$ by affinity chromatography. Carlsberg Res. Commun. 41, 1-14 (1976)

8. JONCZYK, A. \& H.-G. GATTNER: Eine neue Semisynthese des Humaninsulins. Tryptisch-katalysierte Transpeptidierung von Schweineinsulin mit L-Threonin-tert-butylester. Hoppe-Seyler's Z. Physiol. Chem. 362, 1591-1598 (1981)

9. LEE, H.-M. \& J.F. RIORDAN: Does carboxypeptidase $Y$ have intrinsic endopeptidase activity. Biophys. Res. Commun. 85, 1135-1142 (1978)

10. Morithara, K.T. \& H. Tsuzuki: Semisynthesis of human insulin by trypsin-catalyzed replacement of Ala-B 30 by Thr in porcine insulin. Nature 280 . 412-413 (1979)

11. Morihara, K., T. Oka, H. Tsuzuki, Y. Tochino \& T. KANAYA: Achromobacter protease I - catalyzed conversion of porcine insulin into human insulin. Biochem. Biophys. Res. Commun. 92, 396-402 (1980)

12. SCHeChter, I. \& B. Berger: On the size of the active site of proteases. I. Papain. Biochem. Biophys. Res. Commun. 27, 157-162 (1967)

13. Schlichtkrull, J.. J. Brange. Aa. Christensen, O. Hallund, L Heding \& $\mathrm{K}$. JøRGENSEN: Chemical aspects of insulin - antigenicity. Diabetes 21, 649-656 (1972) 